
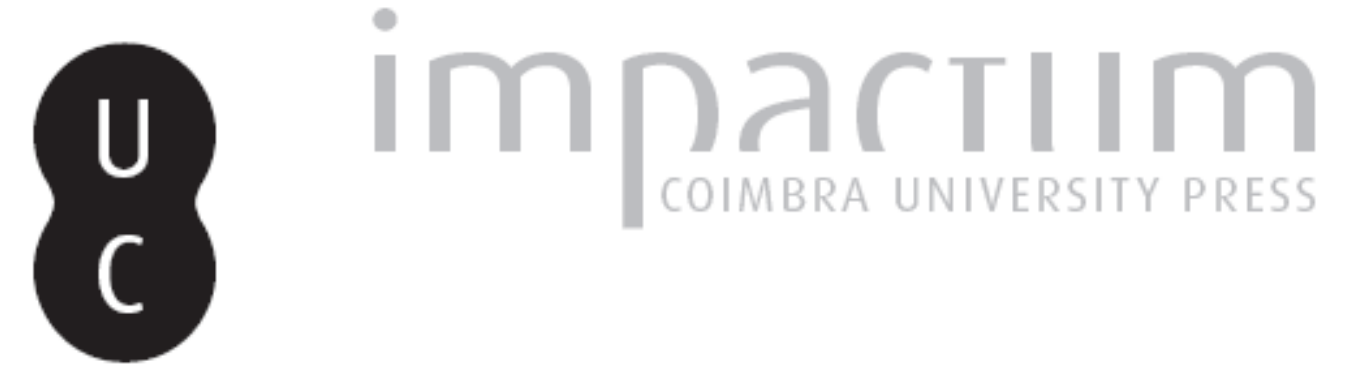

\title{
Ânforas lusitanas do Cerrado do Castelo: Grândola
}

Autor(es): $\quad$ Ferreira, Marisol Aires; Faria, João Carlos Lázaro; Diogo, A. M. Dias

Publicado por: Imprensa da Universidade de Coimbra

URL persistente:

URI:http://hdl.handle.net/10316.2/45529

DOI:

DOI:https://dx.doi.org/10.14195/1647-8657_30_7

Accessed : $\quad$ 26-Apr-2023 01:12:32

A navegação consulta e descarregamento dos títulos inseridos nas Bibliotecas Digitais UC Digitalis, UC Pombalina e UC Impactum, pressupõem a aceitação plena e sem reservas dos Termos e Condições de Uso destas Bibliotecas Digitais, disponíveis em https://digitalis.uc.pt/pt-pt/termos.

Conforme exposto nos referidos Termos e Condições de Uso, o descarregamento de títulos de acesso restrito requer uma licença válida de autorização devendo o utilizador aceder ao(s) documento(s) a partir de um endereço de IP da instituição detentora da supramencionada licença.

Ao utilizador é apenas permitido o descarregamento para uso pessoal, pelo que o emprego do(s) título(s) descarregado(s) para outro fim, designadamente comercial, carece de autorização do respetivo autor ou editor da obra.

Na medida em que todas as obras da UC Digitalis se encontram protegidas pelo Código do Direito de Autor e Direitos Conexos e demais legislação aplicável, toda a cópia, parcial ou total, deste documento, nos casos em que é legalmente admitida, deverá conter ou fazer-se acompanhar por este aviso.

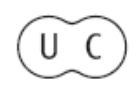


FACULDADE DE LETRAS

INSTITUTO DE ARQUEOLOGIA

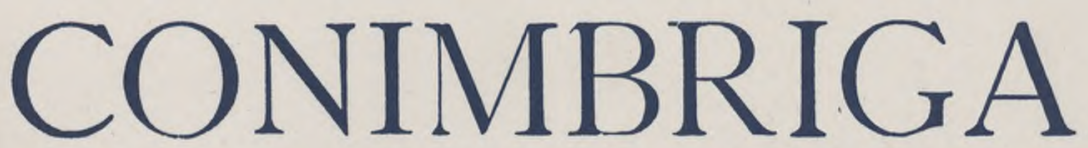

VOLUME XXX

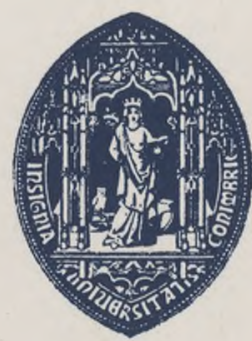

UNIVERSIDADE DE COIMBRA 


\section{MARISOL Aires FERREira}

Técnica responsável pelo sector do Património Cultural da Câmara Municipal de Grândola

\section{Jỗo CARLOS LÁZARo FARIA}

Técnico responsável pelo sector do Património Cultural da Câmara Municipal de Alcácer do Sal

\section{A. M. Dias Diogo}

Assistente da Faculdade de Ciências Sociais e Humanas da Universidade Nova de Lisboa. Bolseiro da Fundação Calouste Gulbenkian

\section{ÂNFORAS LUSITANAS DO CERRADO DO CASTELO, GRÂNDOLA «Conimbriga» XXX (1991), p. 105-108}

REsumo: Os autores publicam quatro fragmentos de ânforas de fabrico lusitano encontrados numa estação da qual se dá notícia neste mesmo volume.

RÉSUMÉ: Les auteurs présentent quatre fragments d'amphores de fabrication lusitanienne, trouvés à Cerrado do Castelo (Grândola). Notice d'une brève campagne de fouilles est publiée dans ce même volume. 
(Página deixada propositadamente em branco) 


\section{ÂNFORAS LUSITANAS DO CERRADO DO CASTELO, GRÂNDOLA}

A estação romana do Cerrado do Castelo, situada na vila de Grândola, foi pela primeira vez referenciada por Leite de Vasconcelos ('). Os materiais que agora estudamos foram recuperados em escavações arqueológicas dirigidas pelos dois primeiros subscritores e realizadas durante o mês de Agosto de 1989.

Neste artigo apenas pretendemos dar conta dos achados anfóricos da campanha de escavações. Resumem-se a fragmentos de quatro ânforas, todas de fabrico lusitano. Este estudo integra-se no projecto de caracterização e sistematização das ânforas lusitanas, que temos vindo a desenvolver ${ }^{(2)}$.

Os fragmentos 1, 2 e 4 são fabricados nas características pastas quartzíticas e micáceas, brandas e porosas, de textura folheada e tonalidades geralmente alaranjadas ou rosadas. $\mathrm{O}$ fragmento $\mathrm{n} .{ }^{\circ} 1$ aproximase do tipo Lusitana 12, que poderá ser o seu protótipo. O lábio, triangular e em fita, de pequeno diâmetro, indica-nos um fabrico inicial entre as Lusitanas 2a, que evolucionaram para um lábio espessado e boleado, de maior diâmetro.

O fragmento $n .{ }^{\circ} 3$ tem a pasta branda, porosa e muito fina, de tonalidades claras, pardacentas e rosadas, que caracterizam um fabrico algarvio. O tipo da ânfora, uma Lusitana 11, é datável da fase " $A$ " de produção.

Q) De Terra em Terra, II, Imprensa Nacional, Lisboa, 1927, p. 94.

(2) Veja-se, por exemplo, de A. M. Dias Diogo e João C. FARIA, Trabalho e produção no Sado durante a época romana, in "Movimento Cultural", 6, Setúbal, 1989, p. 81-92. Trata-se da republicação do Catálogo da exposição com o mesmo título, organizada pela C. M. de Alcácer do Sal, em Maio de 1989. 


\section{CATÁLOGO}

1. Fragmento de boca de Lusitana 2a. Lábio extrovertido, de fita e triangular. Diâmetro do lábio: 16,2 cm. Altura do lábio: $4 \mathrm{~cm}$. Razão diâmetro/altura: 4,05 x.

2. Fragmento de boca de Lusitana 3. Lábio de fita, saliente e pendente.

Diâmetro do lábio: $11 \mathrm{~cm}$. Altura do lábio: $3,3 \mathrm{~cm}$. Razão diâmetro/altura: 3,4 x.

3. Fragmento de boca de Lusitana 11. Lábio extrovertido, em aba, espessado.

Asa cilíndrica, arrancando da sobeira do lábio. Diâmetro do lábio: ? Altura do lábio: ?

4. Fragmento de fundo de Lusitana 4. Cilíndrico e oco. Diâmetro: 4,6 cm.

Altura: 4 cm. Razão diâmetro/altura: 1,15 x.

Conimbriga, 30 (1991), 105-108 

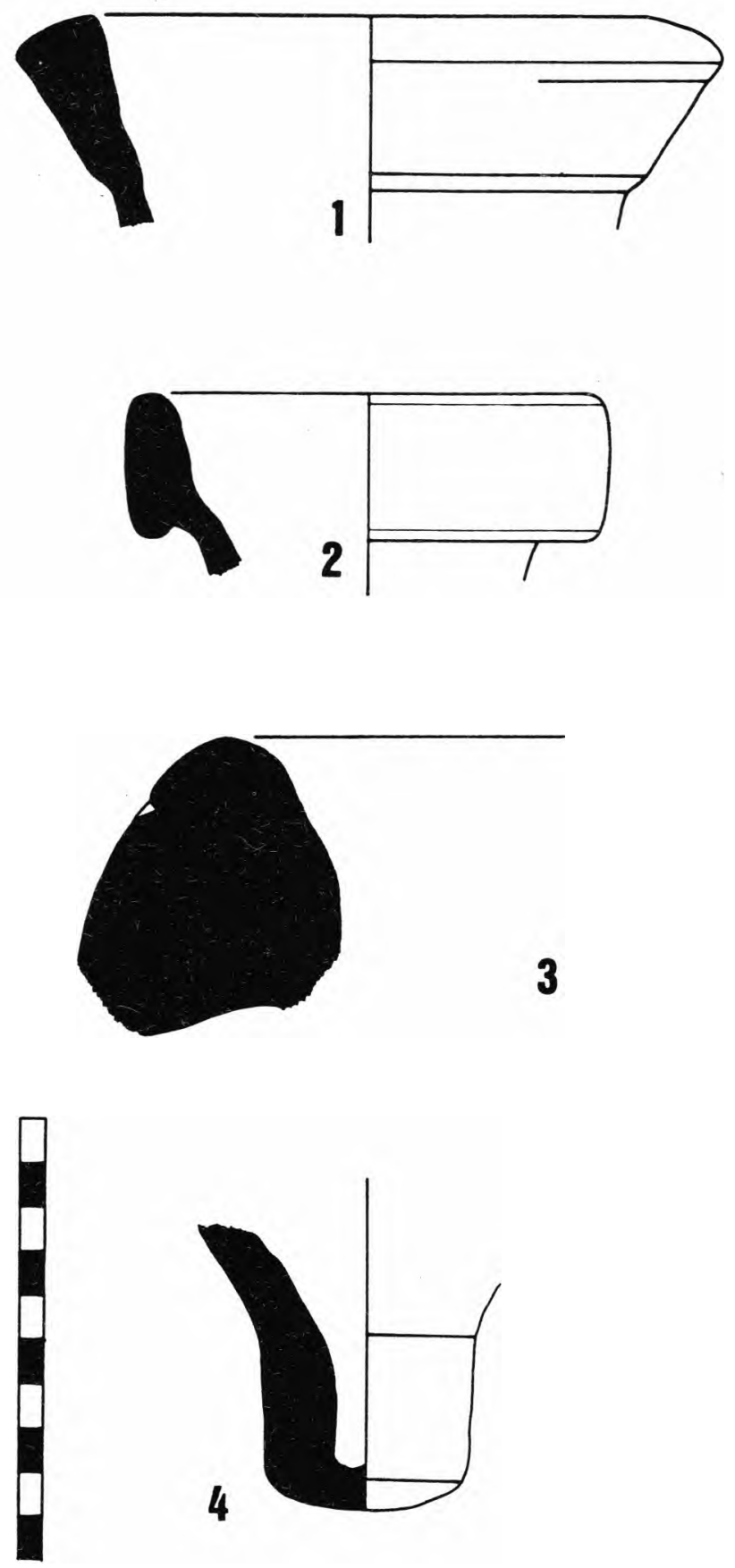

FIG. 1 